\title{
THERMAE PÚBLICAS Y BALNEA DOMÉSTICOS EN LA CIUDAD ROMANA DE CARTHAGO NOVA
}

\section{PUBLIC THERMAE AND DOMESTIC "BALNEA" IN THE ROMAN CITY OF CARTHAGO NOVA}

\author{
MARTA PAVÍA PAGE \\ Universidad de Murcia. C/ Santo Cristo, 1, 30001 (Murcia). \\ Correo-e: marta.pavia@um.es. ORCID: https://orcid.org/0000-0002-6519-872X
}

\begin{abstract}
Resumen: El objetivo de este estudio es plantear un balance y análisis de conjunto de los edificios dedicados al baño e higiene personal documentados hasta la fecha en la colonia romana de Carthago Nova. El estudio comprende tanto los grandes complejos de naturaleza pública, donde el baño constituía un hecho social y cultural, como los pequeños establecimientos domésticos, donde el baño era un acontecimiento privado, aunque no por ello más íntimo o personal.
\end{abstract}

Palabras clave: Carthago Nova, higiene, termas públicas y baños domésticos

\section{INTRODUCCIÓN}

La costumbre del baño, entendida como un binomio entre práctica higiénica y acontecimiento social, fue paulatinamente formando parte de la rutina diaria de los romanos desde la República tardía, periodo en que fueron introducidas en Roma algunas costumbres griegas (Delaine 1985, Nielsen 1989 y 1992 y Fagan 2001). Desde este momento, los pequeños complejos dedicados al aseo de época de Escipión el Africano, descritos por Séneca en una epístola dirigida a Lucilio como "pequeños, oscuros y toscamente revocados de estuco, [...] abastecidos con agua turbia [...] que no brotaba del fondo, ni fluía siempre renovada, puesto que no se consideraba importante que fuese transparente el agua

\begin{abstract}
The aim of this paper is the evaluation and assessment of all those Roman buildings dedicated to bathing and personal hygiene, studied until now in the Roman city of Carthago Nova. The research includes the two main types of Roman baths: large public complexes, where the bath was a social and cultural phenomenon, and small domestic establishments where that practice was a more private event, but certainly not a more intimate or personal one.
\end{abstract}

Keywords: Carthago Nova, hygiene, public baths and domestic balnea

en que se dejaba la suciedad", pasaron a ser los nuevos complejos embellecidos con "valiosos espejos, mármoles de Alejandría, [...] bóvedas revestidas de vidrio, [...] grifos de plata y agua que se precipita ruidosa a modo de cascada" (Sen, Epist. XIII, 86, 5-13).

La proliferación y monumentalización de los complejos termales fue un proceso paralelo a la generalización del uso diario de las instalaciones como parte de la rutina vespertina de los ciudadanos romanos, tal y como afirma Marcial:

"La primera y la segunda hora consumen a quienes se dedican a dar los buenos días, [...] Roma prolonga las diversas ocupaciones hasta la quinta, la sexta es la del descanso de los fatigados, la séptima 
será el final de este, la octava, hasta la novena, basta para los ejercicios con el cuerpo frotado con aceite [actividades realizadas en la palestra y las termas], la novena exige romper con nuestro peso los lechos que se nos han preparado [para la cena]" (Martialis, Ep. IV, 8).

La extensión de esta costumbre como un hecho social fuertemente enraizado en Roma tiene su punto de inflexión en la construcción de las denominadas Termas de Agripa, en el Campo de Marte (Guini 1999, Guidobaldi y Conte 2011-2012, Brundrett y Simpson 1997), consideradas el primer establecimiento termal romano erigido bajo el patronazgo de un miembro de la familia imperial e inicio de una larga relación entre establecimientos termales públicos y élites ciudadanas. Este tipo de munificencia fue practicada no solo por grandes personalidades de la metrópoli, sino también por modestos magistrados y dirigentes locales que promovieron, entre otras, la construcción, cesión de terrenos, restauración, realización de programas decorativos, mantenimiento e, incluso, la subvención del coste de la entrada a las termas como acto evergético (Andreu 2000, Melchor 1992 y 1993, Robinson 1984, Curchin 1983), invirtiendo grandes sumas de dinero en adaptar sus ciudades a su nuevo rol como enclaves romanizados en el tejido urbano del Imperio, fundamentalmente tras el gran proceso de promoción jurídica de época flavia (Kremer 2006, Le Roux 1986, Andreu 2004a y 2004b, García 2001).

En el caso de Carthago Nova, integrada en el Estado romano tras su conquista por Escipión en 209 a.C. (Abascal 2002: 21), la costumbre del baño fue evolucionando de forma similar a la de la propia Roma. Para la etapa fechada entre los siglos II y I a.C., solo se ha localizado un establecimiento termal en la actual calle Serreta. Se trata de un balneum de pequeñas dimensiones, muy rudimentario y de naturaleza privada. Más tarde, tras la deductio pompeyana y en coincidencia con el periodo de esplendor urbanístico de época augustea (Noguera 2012: 144-164), la colonia de Carthago Nova se nutrió de un cierto número de edificios dedicados al baño, tanto de naturaleza pública como privada, edificios que mantuvieron su actividad durante todo el Alto Imperio y, en algunos casos, hasta incluso el siglo IV d.C. Destaca entre ellos por su extraordinario grado de conservación, el complejo público de las denominadas Termas del Puerto, un edificio de dimensiones medias destinado a ofrecer sus servicios, posiblemente, a los habitantes de la ciudad y a gentes recién llegadas a su puerto, muchos de ellos comerciantes de origen griego o itálico (Marín 1988, Domergue 1990, Pérez
Ballester 1998 y Noguera 2012: 129-137 y nota 8) que procedían de lugares donde el baño ya estaba consagrado como un hecho higiénico y social.

Por otro lado, a la adopción cultural y social de la costumbre del baño por los habitantes de la colonia, deben sumarse las propias características del entorno, especialmente aquellas relacionadas con su orografía y con el índice hidrológico y pluviométrico del sureste hispano, las cuales influyeron notablemente en el desarrollo de estos edificios. En el caso de la Cartagena romana, hasta finales de la República tardía la provisión de agua se realizaba a través de cisternas, pozos y aljibes situados en las zonas altas de las colinas que delimitan el espacio urbano, los cuales recogían las escasas, aunque torrenciales, aguas de lluvia, siendo por tanto el suministro hídrico muy limitado (Ramallo y Ros 2012: 86-87). La ausencia de un sistema de aprovisionamiento con un caudal constante y regular debió determinar la demora en la construcción de infraestructuras termales, de naturaleza pública o privada, hasta el momento de la deductio colonial y el subsiguiente proceso de monumentalización y embellecimiento urbano (Abascal 2002, Noguera 2012: 144-164, Noguera y Soler 2011: 1096-1097). Especialmente relevante debió ser la construcción tras la fundación colonial de un acueducto, no documentado arqueológicamente pero sí referido de forma recurrente en crónicas de los siglos XVII al XX (Cascales 1597: 14, conde de Lumiares 1796: 109, González Simancas 1905-1907: 226, Fernández Villamarzo 1907: 293) y citado también en dos inscripciones recuperadas en dos lacus o fuentes públicas localizadas en el centro urbano. La primera de ellas, procedente de la ladera occidental del Cerro de la Concepción y la segunda hallada en la plaza Roldán, a los pies del Monte Sacro, conmemoran la construcción del referido acueducto y las fuentes: [...] aquam adducenda(am) laqusq(ue) fac(iendos) coer(avit) (Ramallo y Murcia 2010: 249-252). Con la construcción de las primeras infraestructuras de abastecimiento hídrico y los edificios dedicados al baño debemos relacionar también la construcción de la primera red de saneamiento y alcantarillado, indispensable para el buen funcionamiento y salubridad de la ciudad (Marín y De Miquel 1995, Egea 2001-2002, Ramallo y Ros 2012 y Egea et al. 2011). La dotación de la red de saneamiento fue posible mediante cloacas construidas con lajas de piedra y muros de mampostería (Egea 2004: 85-86) y cubiertas por el pavimento de las principales calles, permitiendo de esta forma la retirada de los residuos y aguas sobrantes (aqua caduca), en concreto hacia la zona del mar y del Almarjal. 


\section{LOS COMPLEJOS TERMALES DE CARTHAGO NOVA}

Procedemos ahora al análisis individualizado de los complejos termales localizados hasta el momento en la colonia de Carthago Nova, diferenciando los de naturaleza pública de los balnea domésticos.

\section{Termas Públicas}

1. Las Termas del Puerto (Insula I del Molinete) (fig. 1a, fig. 2)

El complejo se encontraba situado en pleno corazón de la colonia, a mitad de camino entre el puerto y el foro, razón por la que debió de ser uno de los establecimientos termales más concurridos. Su adscripción como terma pública fue corroborada por la placa epigráfica en mármol (fig.2), documentada durante las labores de excavación del edificio, en la que puede leerse $R[. .$.$] / loco$ [dato]/ d(ecreto) d(ecuriorum) [d(ono) d(edit)] (Abascal 2009: 256).

La primera actuación arqueológica en el edificio tuvo lugar en 1968 en la Plaza de los Tres Reyes y estuvo a cargo de P. San Martín Moro (1973, 1985a y 1985b), documentándose un praefurnium y parte del caldarium de las termas. Nuevos trabajos se acometieron en el lugar en 1982 por parte de M. Martínez Andreu, que excavó dos solares colindantes en la calle Honda, $n^{\circ} 11$ y 13 , los cuales permitieron documentar varias estancias del complejo (Martínez Andreu 1997: 12). Los trabajos arqueológicos en la zona, englobada actualmente en el Parque Arqueológico del Molinete, continuaron en 2008 y durante cuatro años se excavó, estudió y puso en valor una manzana de época cesariano-augustea (denominada Insula I) en cuya mitad occidental se terminaron de documentar los restos del edificio termal, siendo sus dimensiones actuales conservadas de, aproximadamente, $1200 \mathrm{~m}^{2}$ (Madrid et al. 2015: 15).

Las salas dedicadas al baño se disponían siguiendo un eje orientado en sentido norte-sur, con un recorrido de sentido retrógrado y un esquema de tipo lineal-simple, articulado en base de un eje axial principal a lo largo del cual se disponen las estancias principales del complejo, es decir, frigidarium, tepidarium y caldarium; en un segundo eje más corto se sucedían una serie de estancias complementarias, a saber, un segundo tepidarium y una sudatio.

El recorrido del baño daba comienzo en el frigidarium-apodyterium (F/A) rectangular, situado en el extremo septentrional del edificio, un ambiente frío combinado, muy utilizado en época augustea, que hacía las veces de sala de recepción de usuarios y vestuario. En el lado oriental de este ambiente se disponía una pequeña piscina cuadrangular, con tres peldaños de acceso al interior, utilizada para el baño de inmersión y asiento. Desde la sala fría se accedía también al denominado tepidarium I o sala templada, con una función de antesala del caldarium o sala cálida, conservada en buena parte bajo la actual calle Honda; tras esta y abierta a una de las calles principales de la colonia, se constataron las estancias de servicio y mantenimiento, así como los hornos, de los cuales se conserva el praefurnium de uno de ellos, el basamento de sustentación de un depósito de agua y unas posibles letrinas.

Como hemos referido, paralelo a este eje principal discurría otro secundario, con acceso también desde el frigidarium-apodyterium, con dos salas calefactadas de pequeñas dimensiones: un segundo tepidarium, también sin bañera, de planta cuadrada, y una posible $s u$ datio o sauna de calor seco sin trazas arquitectónicas de solium. La sala identificada como sudatio lindaba al sur directamente con la boca de un praefurnium y el resto de estancias de servicio, a las cuales hemos aludido al referir los hallazgos bajo la actual calle Honda y plaza de los Tres Reyes.

El complejo termal contaba también con un gran acceso monumental, el cual pudo funcionar también como palestra, de $580 \mathrm{~m}^{2}$, concebido a modo de peristilo y situado al este de las salas de baño. Es un ambiente de planta rectangular, pendiente hacia el suroeste, porticado en sus cuatro lados y con un espacio central al aire libre pavimentado con ladrillos dispuestos según la técnica del opus spicatum. Los deambulatorios de los lados sur, este y oeste eran de una sola nave, estaban pavimentados con suelos de mortero y contaban con cubiertas a una vertiente. El orden de las columnas de estos pórticos era jónico, siendo los capiteles y las basas de arenisca estucada y pintada. En el lado norte, en cambio, se construyó un pórtico de doble nave, posiblemente para sustentar una segunda planta. El pórtico contaba con dos filas de columnas: una central formada cuatro columnas de orden jónico y una exterior, con dos columnas jónicas en los extremos y dos columnas centrales corintias. Estas últimas contaban con fustes de travertino rojo de La Almagra (Mula) y capiteles y basas de mármol de Luni-Carrara. En este espacio, que actuó de cabecera del peristilo, pudo alzarse -aunque no es cosa segura- la estatua de una divinidad o de un miembro de la casa imperial deificado, de la cual solo se ha recuperado en los niveles de expolio 


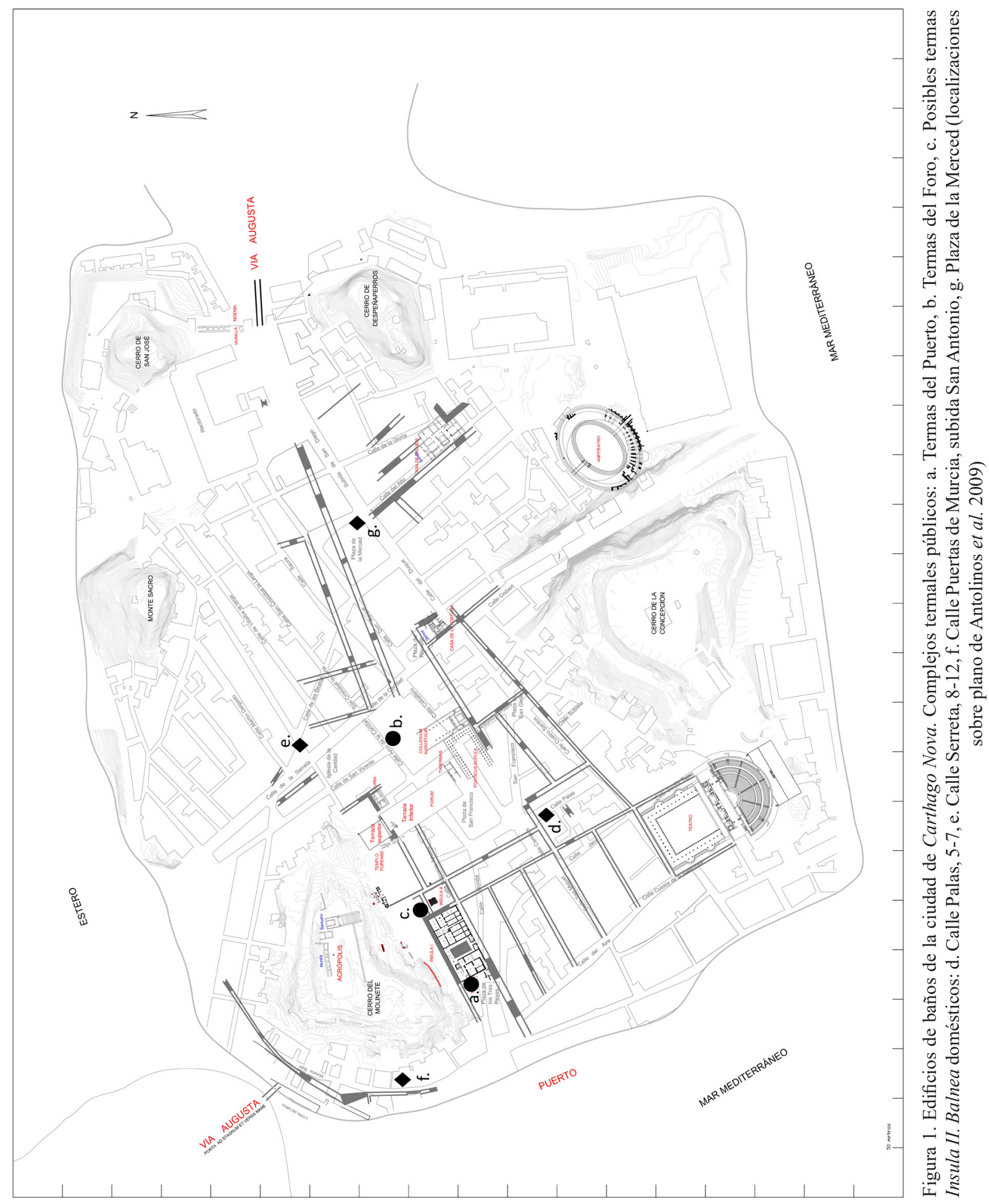


del siglo V d.C. una cornucopia (fig. 3) ricamente decorada con motivos propios del lenguaje artístico augusteo (Noguera et al. 2011: 92-97).

\section{Las Termas del Foro (fig. 1b, fig. 4)}

El recinto termal, localizado en parte en la calle Arco de la Caridad, $n^{\circ} 8,10$ y 12, engloba una superficie de, aproximadamente, $620 \mathrm{~m}^{2}$. Los trabajos de excavación dirigidos por Lorenzo Suárez Escribano se acometieron entre septiembre de 2010 y mayo de 2011. El edificio de baños, con orientación nordeste-suroeste, ha sido interpretado como uno de los grandes conjuntos termales públicos de Carthago Nova, en particular por sus dimensiones, que se han estimado en aproximadamente $3400 \mathrm{~m}^{2}$, y sobre todo por su ubicación en la trama urbana. En concreto, está situado al sureste del foro, en las inmediaciones de uno de sus lados largos, lindando con dos de los edificios públicos más importantes, la

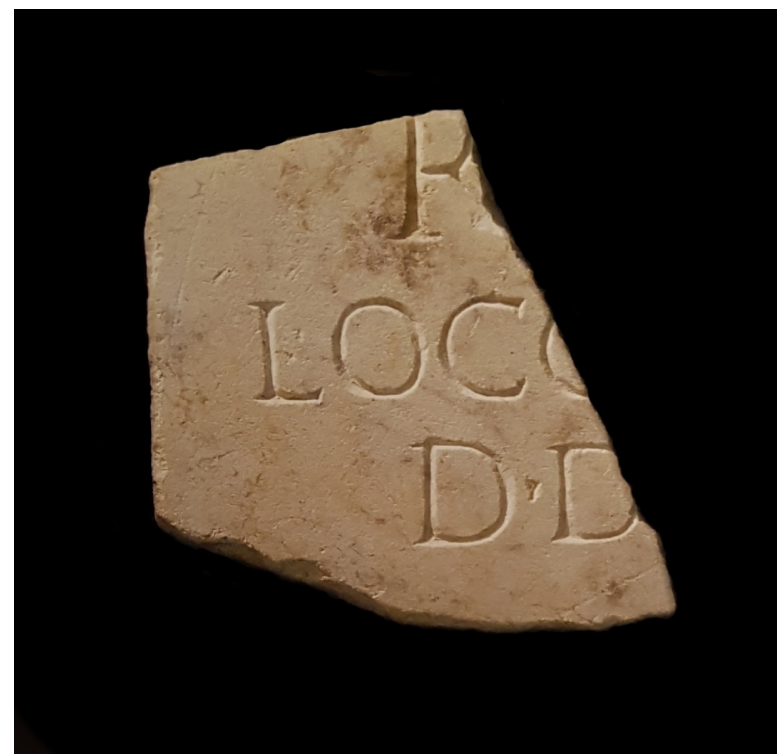

Figura 2. Placa epigráfica que refleja la titularidad pública de las Termas del Puerto (fotografía J.F. González)

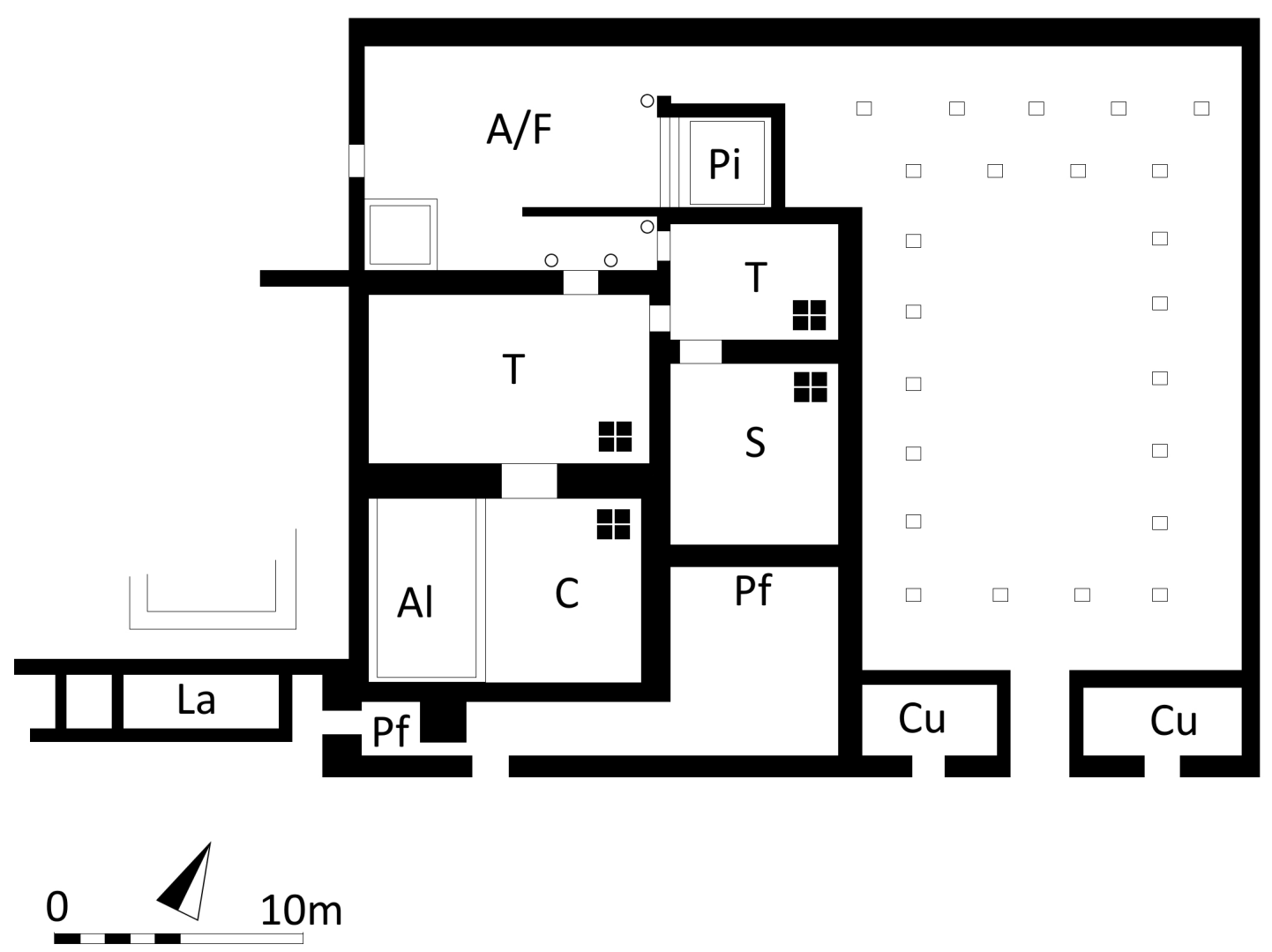

Figura 3. Planta de las Termas del Puerto, Carthago Nova (elaboración propia a partir de Pérez Cuadrado 2009) 


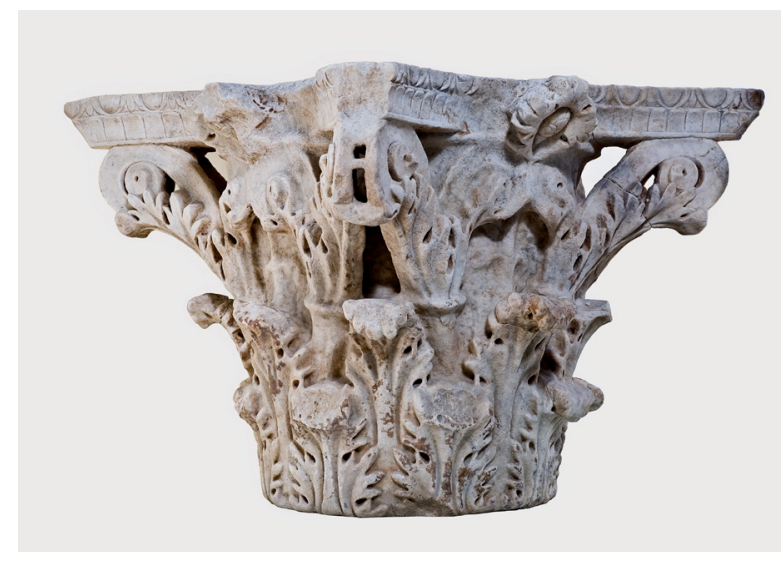

Figura 4. Capitel corintio documentado en el pórtico de las Termas del Puerto (fotografía J. F. González)

curia, situada al noreste, y la sede de los Augustales, emplazada al sur (Suárez 2011: 123). La ausencia de la planta completa del edificio y la dificultad para interpretar algunas de las estancias excavadas impide, por el momento, el establecimiento de una hipótesis para el recorrido del baño, así como una adscripción tipológica precisa del complejo.

La primera sala, denominada por su excavador como Ambiente 1, es una estancia de grandes dimensiones pavimentada con mortero hidráulico y estucada en blanco. Dada la ausencia de hipocausto debe tratarse de uno de los ambientes fríos del edificio; sin embargo, no se ha constatado en ella resto alguno de estructuras hidráulicas relacionadas con el agua y el baño. La segunda sala, también pavimentada con mortero hidráulico, contaba con un gran banco corrido de $3 \mathrm{~m}$ de longitud y 0,6 m de anchura en dos de sus lados, por lo que podríamos apuntar una relación hipotética entre esta sala y el apodyterium del complejo, aunque la ausencia de más datos, especialmente en lo referente a su relación con las estancias adyacentes, impide aseverar esta hipótesis (Suárez 2011: 114-115). La tercera sala, pavimentada con mortero de peor calidad, fue identificada en excavación como ambientes 3 y 6 , cortados en el siglo XVI por el baluarte defensivo de Lorenzo Possi (Suárez 2005 y 2006 y Munuera 2003). Tiene planta alargada y unas dimensiones totales de $11 \mathrm{~m}$ de longitud por $4 \mathrm{~m}$ de anchura. En su esquina noreste fue hallado uno de los praefurnia del complejo termal (Suárez 2011: 116 y 120), razón por la cual su funcionalidad debe relacionarse con los hornos destinados al caldeo de las estancias calefactadas y, por ende, con la zona de servicio o propnigeum. El acceso a la zona de hornos se realizaba a través del ambiente 7 , un pequeño espacio que comparte características y pavimento con la anterior, formando también parte del entramado de estancias de servicio (Suárez 2011: 120).

La siguiente sala, con unas dimensiones aproximadas de $108.56 \mathrm{~m}^{2}$, ha ido interpretada como un caldarium, debido a sus dimensiones y a la presencia de sistema de calefacción con hypocausis; del hypocaustum se han recuperado algunas de las pilae, formadas por ladrillos superpuestos trabados con cal y arena. Entre los ladrillos conservados destacan los circulares de $30 \mathrm{~cm}$ de diámetro y los rectangulares, pedales y bipedales, que debido a su menor proporción y a su situación en zonas concretas de la estancia podrían ser fruto de una remodelación o reparación puntual del entramado de pilae, cuya altura sería de $0,90 \mathrm{~m}$. En esta sala se ha constatado también parte de un alveus de grandes dimensiones $(6,90$ por $1,85 \mathrm{~m})$, revestido de mortero hidráulico y con media caña en las juntas para evitar filtraciones. La siguiente estancia, ambiente 15, podría ser un patio o espacio abierto, pudiendo su uso asociarse a la realización de algún tipo de actividad deportiva al aire libre, o bien al esparcimiento o solarium. Con una superficie de $22 \mathrm{~m}^{2}$, está atravesada en su parte oriental por una canalización de desagüe, que nace de la estancia siguiente (ambiente 12); ha sido puesta en relación con una pileta de ladrillo trabada con mortero y recubierta del mismo material, probablemente una pequeña piscina para el baño de asiento, aunque al quedar la mayor parte de la estancia bajo el perfil de la excavación no pueden apuntarse más datos sobre sus características tipológicas y formales (Suárez 2011: 118-119).

El resto de estancias documentadas no han podido ser excavadas en extensión, por lo que su funcionalidad y relación con el complejo termal son, a día de hoy, complejas de establecer.

\section{Posible edificio termal público de la Insula II del Molinete (figs. 1c y 5)}

Los restos sido localizados e identificados parcialmente durante los trabajos de excavación y adecuación de la denominada Insula II del Molinete, una pequeña manzana ubicada en las inmediaciones del foro y delimitada por varias calles, en la que se ha constatado un santuario posiblemente consagrado a los dioses Isis y Serapis. El edificio de baños se encuentra situado en la esquina noroccidental de la manzana y aunque solo ha podido ser excavado de forma parcial, por encontrarse bajo la antigua calle de la Aurora, en la ladera del Cerro del Molinete, han sido documentadas la boca de uno de sus 

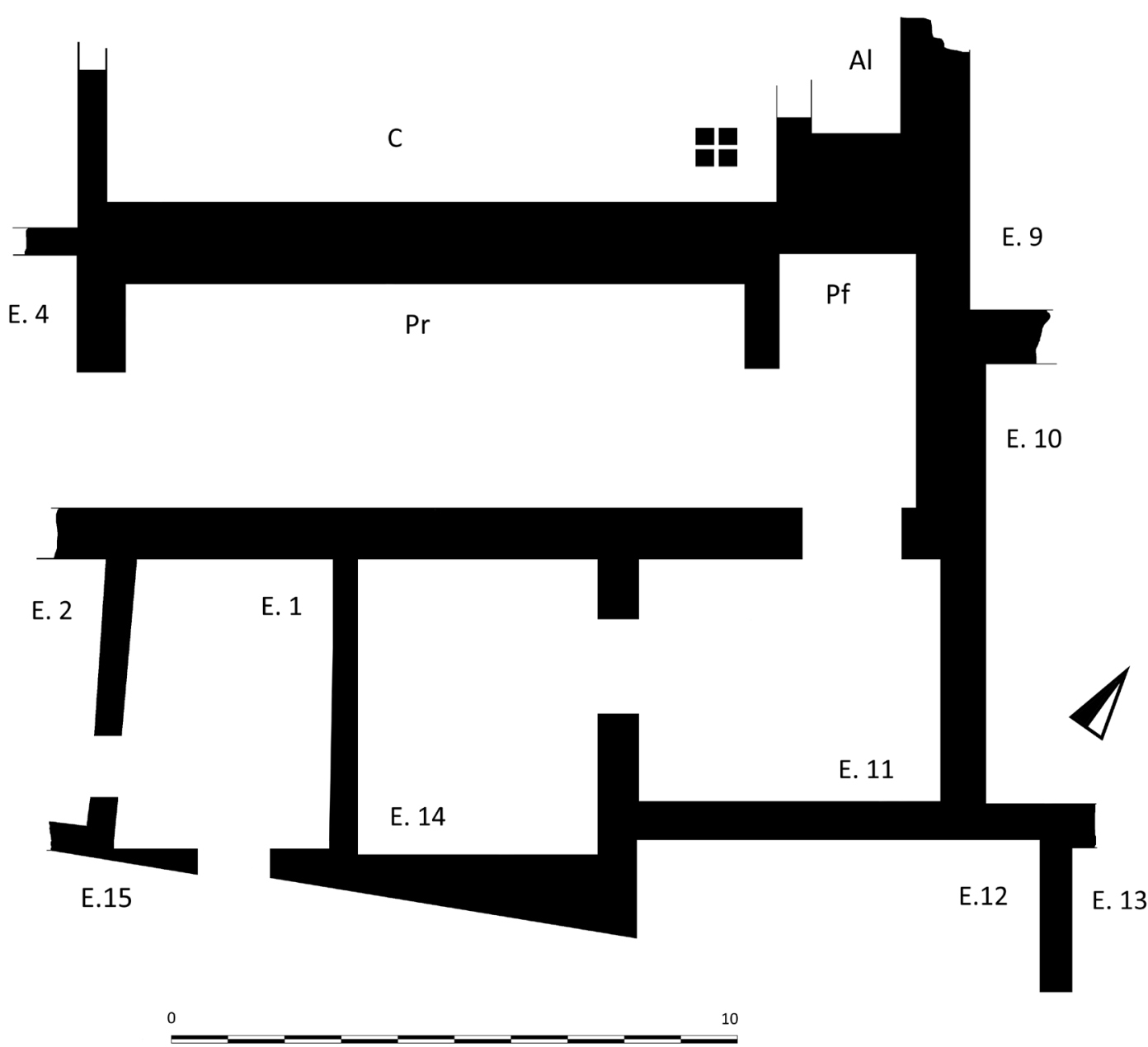

Figura 5. Planta de las Termas del Foro de Carthago Nova (modificado a partir de Suárez 2011).

praefurnia y parte del área de servicio, pertenecientes a la primera fase del edificio, y una piscina de agua fría, localizada un poco al oeste. La piscina contaba con tres peldaños de acceso y revestimiento de estuco, siendo adscribible a la fase final del mismo.

\section{Balnea Domésticos}

1. Calle Palas 5-7 (figs. 1d, 6 y 7)

Estos baños, de considerables dimensiones $\left(184 \mathrm{~m}^{2}\right)$, fueron documentados en 2005 por un equipo dirigido por Juan Antonio Antolinos. La instalación termal contaba con varias salas, de las cuales se excavaron cuatro.
La construcción del complejo ha sido fechada en las últimas décadas del siglo I a.C., mientras que su amortización ha sido datada a mediados del siglo II d.C. gracias al material cerámico documentado en excavación (Antolinos 2006a: 101 y 103).

La primera estancia, de planta cuadrangular y con unas dimensiones de $2,10 \times 1,70 \mathrm{~m}$, contenía el praefurnium; el paso de calor a la estancia contigua tenía un arco, de 0,50 m de anchura, construido con ladrillos y bloques irregulares de andesitas, calizas y caliches trabados con mortero de cal y arena. El horno alimentaba un canal de forma abovedada, permitiendo el caldeo de la estancia adyacente situada al noreste.

La sala adyacente, identificada como un pequeño tepidarium de 5,22 $\mathrm{m}^{2}$, contaba con un sistema de hipocausto 


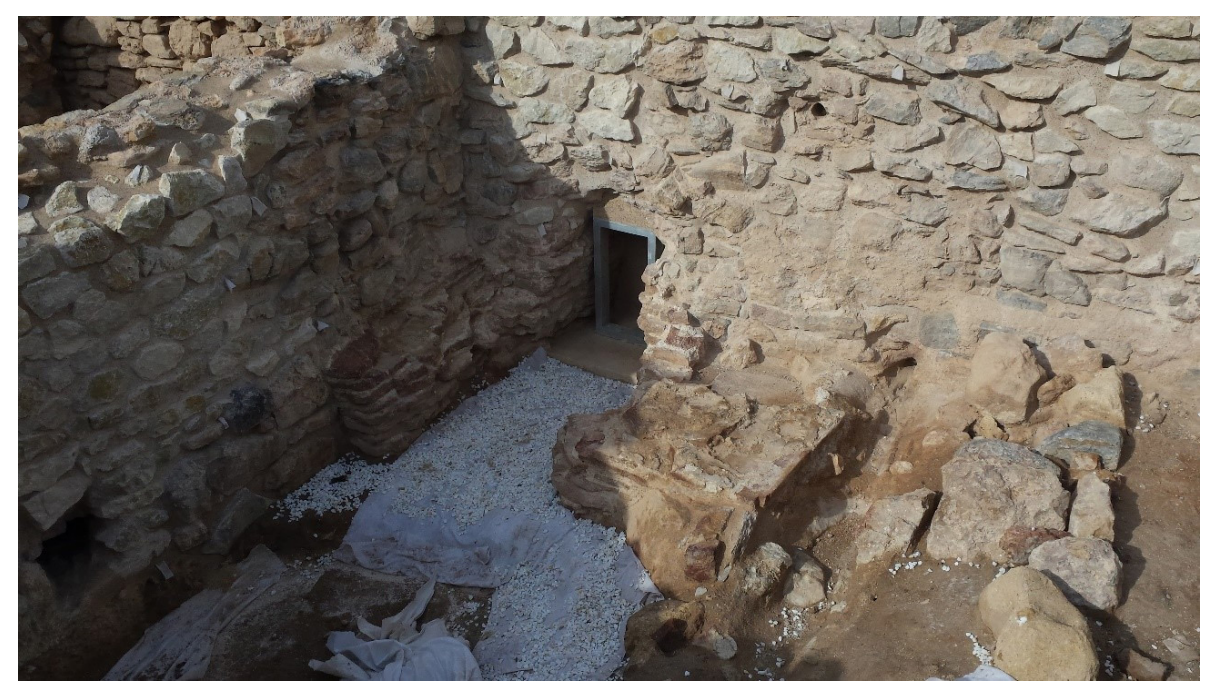

Figura 6. Posibles termas de la Insula II. Boca del praefurnium.

asentado sobre un area de opus signinum y un entramado de pilae restituido e a partir de las columnillas documentadas in situ y las improntas conservadas. Las pilae, distribuidas en cuatro series de tres filas, estaban construidas mediante la alineación de ladrillos bessales y sustentaban el suelo por el que circulaban los bañistas (suspensura), que no ha podido ser documentado. La calefacción parietal de la estancia se realizaba

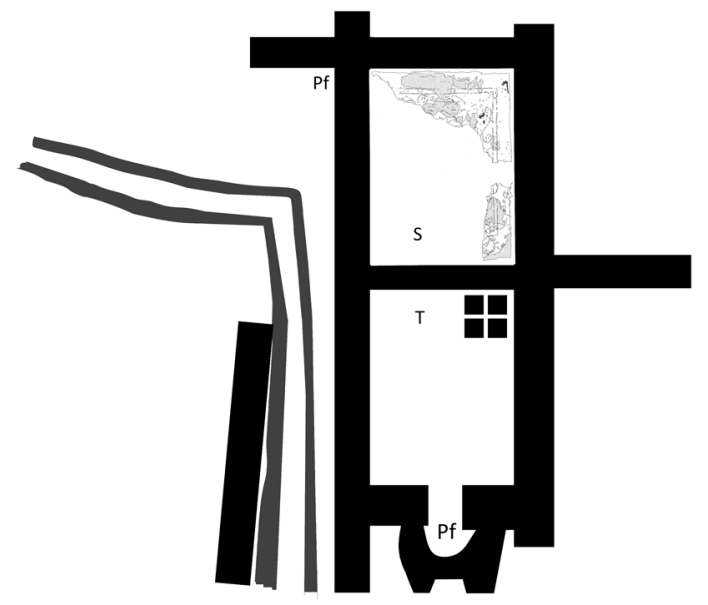

Figura 7. Balneum doméstico de la calle Palas 5-7 (modificado a partir de Antolinos 2006b). gracias a los clavi coctiles y los tubuli cuadrangulares, los cuales han podido ser documentados entre los materiales cerámicos recuperados del complejo. Al noreste del tepidarium se disponía otra estancia, también calefactada, aunque en este caso no se ha documentado el hipocausto. Con unas dimensiones de $5,40 \mathrm{~m}^{2}$, estaba pavimentada con un signinum decorado con teselas y dotado de moldura de media caña en la unión de las paredes con el suelo en tres de sus lados. A pesar de la ausencia del sistema de hipocausto la sala debía alcanzar altas temperaturas: por un lado, obtendría calor por la pared compartida con el tepidarium, y por otro, se caldearía gracias a un segundo praefurnium documentado en su esquina norte y que posteriormente describiremos. Por último, las quemaduras documentadas en el suelo de la sala sugieren el empleo de braseros metálicos para completar el caldeo, lo que en su momento permitió que la sala fuese identificada como una posible sudatio (Antolinos 2006a: 103).

El caldeo de la sudato se realizaba a través de un canal abovedado, de $1 \mathrm{~m}$ de longitud construido con ladrillos pedales, que desembocaba en un segundo praefurnium, situado al norte. Por otro lado, el praefurnium debió de servir también para calentar un depósito de agua, tal y como apunta la fistula plumbea documentada junto al mismo y cuyo uso deber ser relacionado con un alveus o bañera de agua caliente, situada posiblemente al noreste de la sudatio.

Los dos praefurnia estaban comunicados por un área de servicio paralela a las dos estancias de baño descritas, por la que también discurría un canal de desagüe de las aguas residuales del baño, de más de $4 \mathrm{~m}$ de longitud, sección cuadrangular y cubierto con grandes lastras 
de caliza que también hacían las veces de nivel de circulación de la zona de servicio (Antolinos 2006a: 104).

\section{Calle Serreta, n. ${ }^{\circ} 8-12$ (fig. 1e)}

La excavación arqueológica en estos solares fue realizada en dos fases: la primera, entre noviembre y diciembre de 1983, tuvo lugar en los solares $n^{\circ} 8$ y 10 de la calle Serreta, mientras que la segunda, desarrollada entre febrero y abril de 1986, y se practicó en el n 12 de la misma calle (Martín y Roldán 1997: 74). El pequeño establecimiento balnear, documentado de forma parcial, fue localizado en la parte posterior del solar junto a la medianera sur, cercana al perfil final de excavación. La estancia excavada, probablemente un caldarium o tepidarium, contaba con un hipocausto con area de mortero sobre la que apoyaban las pilae, construidas con ladrillos cuadrangulares de pequeñas dimensiones. El suelo de la suspensura, identificado en una de las esquinas de la sala, también era de opus signinum y contaba con decoración de teselas blancas. Lamentablemente, la escasa entidad de los restos documentados y la ausencia de material cerámico asociado impiden proporcionar al complejo una cronología concreta (Martín y Roldán 1997: 90).

En relación con este pequeño conjunto, en 2007 fue documentada parte de la canalización que posiblemente garantizaría el abastecimiento hídrico de las estancias de baño. Esta, construida con bloques de arenisca, fue localizada en la calle Serreta, esquina con Martín Delgado, a los pies de una gran fuente monumental o ninfeo (López y Egea 2008), del cual nacían dos ramales de un specus, uno en dirección sur y otro en dirección norte, en concreto hacia este conjunto (Egea 2011: 86).

\section{Calle Puertas de Murcia, esquina} subida San Antonio (fig. 1f)

Durante una intervención arqueológica entre marzo y abril de 2005 se documentaron dos estancias calefactadas, en uso durante los siglos I y II d.C. Las salas, de pequeñas dimensiones, podrían identificarse como un tepidarium y un caldarium de uso doméstico. Ambas tienen sistema de hypocausis, construido mediante pequeñas arcadas que sustentarían el pavimento de la suspensura realizado con mortero hidráulico.

En una de las estancias, identificable posiblemente como caldarium, pudo constatarse también de forma parcial, por encontrarse bajo el perfil de excavación, una pequeña pileta revestida de mortero y con las juntas protegidas con una media caña. Probablemente, se trate del alveus, del que se conoce también un pequeño orificio o canal en el fondo que comunicaría directamente con el pavimento de la sala, pudiendo tratarse del desagüe, ya que en algunos complejos termales el agua desechada de las piscinas era utilizada en la limpieza de los suelos del complejo (Fernández 2006: 111-112).

\section{Plaza de la Merced, n. ${ }^{\circ} 10$ (fig. 1g)}

En el centro del solar, excavado en 1970 según noticia de P. San Martín, fue hallada parte de una calzada romana enlosada, de dirección este-oeste, y los restos de una estancia de pequeñas dimensiones, pavimentada con opus spicatum, en la que pudo documentarse una bañera o pileta y dos basas de columna (San Martín 1985: 134). La brevedad de la noticia impide aseverar su pertenencia o no a un balneum doméstico, si bien podría estar relacionado con un pequeño establecimiento de este género fechable en época tardorrepublicana (Ramallo y Ros 2012: 89).

\section{EVOLUCIÓN CRONOLÓGICAY Y CARACTERÍSTICAS ARQUITECTÓNICAS: TIPOLOGÍA, DECORACIÓN Y MATERIAL CONSTRUCTIVO}

Los complejos termales constatados hasta la fecha en Carthago Nova constituyen un fiel reflejo de la generalización en la ciudad de la costumbre romana del baño. La implantación y evolución de los establecimientos arranca en época tardorrepublicana, momento en que los primeros establecimientos termales, los balnea domésticos, son introducidos en Hispania desde la península itálica, fundamentalmente desde la zona de Campania (García-Entero 2005: 729-737). El modelo, en plena fase de formación, saltará pronto las fronteras de la domus privada para convertirse en un edificio público de gran transcendencia urbana, heredero de los antiguos balaneia griegos, aunque arquitectónicamente mejorado gracias a los aportes itálicos, en particular a la introducción del sistema de hypocausis (Eschebach 1979 y Nielsen 1985: 81-82), que contribuyó a la consolidación del modelo arquitectónico ya plenamente funcional en época proto-augustea.

En el caso de Carthago Nova, la información disponible hasta el momento nos permite vincular la paulatina introducción y evolución de los complejos termales 
con la escasez de recursos hídricos disponibles, derivados de una climatología adversa, lo cual determinó un retraso evidente en la introducción de este tipo de complejos, que debieron estar muy limitados hasta la construcción del acueducto. Así, en época tardorrepublicana solo conocemos en la ciudad un conjunto termal, el balneum doméstico de reducidas dimensiones localizado en la calle Serreta, en la falda del Monte Sacro, fechado en un momento impreciso entre los siglos II y I a.C.

Unos años más tarde, la construcción del acueducto a mediados del siglo I a.C. y el inicio de un abastecimiento hídrico fluido en la ciudad (Ramallo y Murcia 2010), permitieron paliar los efectos de la desfavorable climatología del sureste hispano. Sin embargo, a pesar del gran avance que supuso su construcción, el problema del agua en la zona debió seguir siendo una constante histórica, limitándose su uso, primero a las instalaciones públicas, como fuentes, termas, lavanderías y establecimientos industriales, y después, al uso de particulares. De esta situación deja constancia, con carácter general, Frontino en relación con el ordenamiento jurídico de la conducción y salvaguarda de los acueductos:

"El primer aspecto trata de la limitación de los particulares dentro de la cuantía de agua que les ha sido concedida. [...] para que ninguna persona privada encauce otra agua que la que cae del depósito a tierra, es decir el agua que había rebosado del depósito, a la que nosotros llamamos excedente y fijándose un impuesto que debiera pagarse al tesoro público, $[\ldots]$ vigilando que nadie tome agua pública sin habérsele concedido y en una cantidad mayor de la que ha solicitado" (Frontinus, De Aquaeductu Urbis Romae, XCIV, 1-4, CIII, 5).

Por tanto, la dificultad en la consecución de un permiso para el uso privado del agua pública determinó la escasez de baños domésticos, sobre todo en aquellos lugares donde la disponibilidad era limitada, primando la construcción y el uso de establecimientos públicos.

En el caso de Carthago Nova, la mayor parte de los complejos termales, tanto de naturaleza pública como privada, se desarrollan a partir del periodo augusteo. Los primeros balnea construidos en este momento fueron los de la calle Palas y la plaza de la Merced, ambos de cronología cercana al cambio de Era. Unas décadas más tarde, fueron construidos los complejos termales públicos de la colonia, fechándose el primero de ellos, las Termas del Puerto, en los primeros decenios del siglo I d.C., y posteriormente, aunque en esta misma centuria, las denominadas Termas del Foro.
La mayor o menor longevidad de los complejos puede ponerse en relación, de nuevo, con la disponibilidad hídrica y su accesibilidad, constatándose el abandono de los baños domésticos en fechas cercanas al siglo II d.C., momento en que las estancias son amortizadas y cambian de uso. Frente a ello, los complejos públicos experimentan un segundo momento de auge, con importantes reformas y restauraciones, como se observa en las Termas del Puerto, donde se constata una repavimentación del frigidarium con grandes lastras marmóreas y una reparación de la gran sala porticada al aire libre. Ambas reformas han sido fechadas gracias a la decoración pictórica del peristilo, asociada a estos trabajos, en época trajano-adrianea. La preeminencia de los complejos públicos de la colonia se aprecia también en su perduración en el tiempo; tanto las Termas del Puerto como las del Foro tuvieron una amplia vida útil que se extendió, tal y como apuntan los contextos cerámicos asociados a su amortización, hasta el siglo IV d.C., momento en que cesó el uso de las instalaciones (Suárez 2011: 115, Noguera et al. 2011: 113, Madrid et al. 2014: 20 y Pavía 2015: 2).

Desde la óptica tipológica, cabe destacar en los complejos estudiados la reiteración sistemática de esquemas predeterminados, de concepción lineal-simple y recorrido retrógrado, con la sucesión de estancias alineadas sobre un mismo eje e idéntico itinerario para la entrada y la salida (Krencker 1938); si bien es cierto que los restos conservados, especialmente los relativos a los complejos termales de ámbito doméstico, no son lo suficientemente completos como para ser tomados como totalmente representativos para un análisis tipológico.

En todo caso, la repetición del esquema lineal-simple con circulación interior retrógrada en complejos de naturaleza pública es tema recurrente en toda la geografía peninsular, dada su sencillez y por ser un esquema fácil de ejecutar, más barato, práctico y funcional (Fernández Ochoa et al. 2000: 63); está constatado, entre otros, en complejos como las Termas Monumentales de Segobriga (Abascal et al. 2004: 27), Los Arcos II de Clunia (Fernández-Ochoa y García-Entero 1999: 142), las Termas I y II de Labitolosa (Labarthe et al. 2000: 196), la fase I de las termas de Bilbilis (Martín-Bueno y Liz 1999: 256-257) o en las termas de Baelo Claudia (Gómez 2013: 167), todos ellos fechados entre los siglos I y II d.C. (Fernández Ochoa et al. 2000: 60-61).

En cuanto a los balnea privados urbanos, la representatividad de este esquema tipológico es también evidente, documentándose por ejemplo en la Casa del Mosaico del Oso y los Pájaros de Asturica Augusta (Fernández-Ochoa y García-Entero 1999: 153) y en 


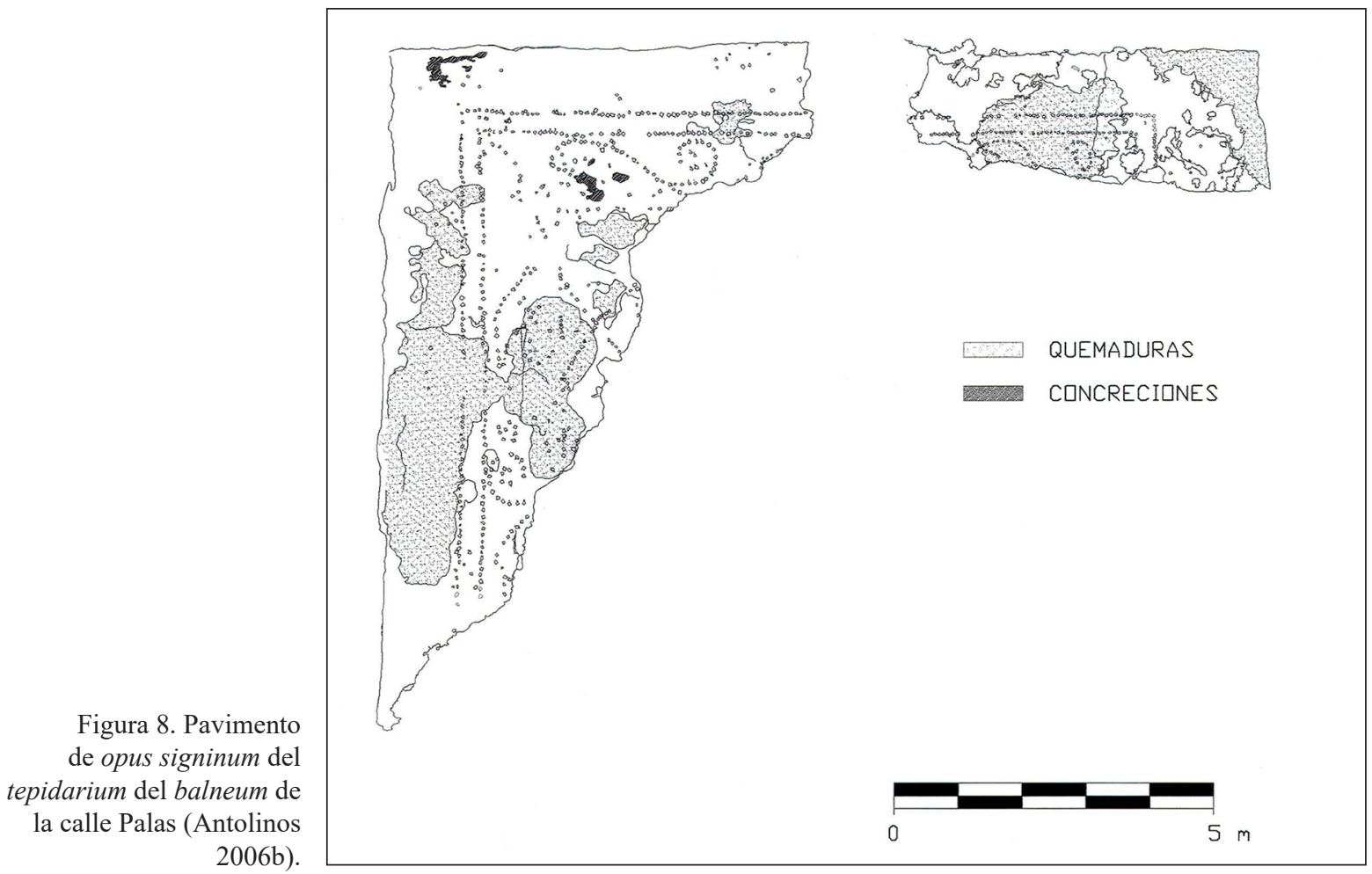

los balnea de la Casa 2B de Ampurias (García-Entero 2005: 227), de la Casa de Los Mármoles y del Anfiteatro (García-Entero 2005: 541 y 552), ambas de Mérida, así como en la Casa de la Exedra de Italica (García-Entero 2005: 717). Cronológicamente, este esquema fue ampliamente utilizado desde época republicana hasta el siglo II d.C., siendo de nuevo retomado a partir del siglo IV d.C. (García-Entero 2005: 747-749).

En Carthago Nova parece una tendencia recurrente la distribución u orientación de las estancias de baño siguiendo un eje longitudinal norte-sur, documentado por ejemplo en el balneum de la calle Palas o en el caso de las Termas del Puerto, las mejor conocidas, donde este esquema puede apreciarse de manera nítida en el frigidarium o sala fría, situado al norte del conjunto, en un lugar de escasa insolación y protegido por la ladera de la colina, mientras que las habitaciones calefactadas (tepidaria, sudatio y caldarium) se sitúan en una zona más al sur (Ramallo 1989: 176). Este tipo de disposición concuerda además, con las normas proporcionadas por Vitruvio, que reseña al respecto:

"En la sala de los baños calientes y en la de los baños templados la luz debe entrar por el lado del poniente; si la naturaleza o situación del lugar no lo permite, en ese caso tomará la luz desde el mediodía, ya que el tiempo fijado para los baños va desde el mediodía hasta el atardecer" (De Arch. V, 10, 1).

Los programas decorativos (Arasa 2004, Koppel 1995 y 2004, Guiral 2000, García Martín 2007, Candilio 1991, Manderscheid 1994, Hartmann 1995 y Pérez Olmedo 1996) de los edificios termales de la colonia se componen de ornamentación escultórica, de una parte, y arquitectónica, parietal y pavimental, por otra. En el primer caso, destacan los elementos documentados en las Termas del Puerto, sobresaliendo la cornucopia marmórea recuperada en los niveles de amortización del espacio porticado, y parte de un clipeum, hallado en 1982 sobre el suelo del frigidarium; el clípeo está enmarcado por un festón de hojas de laurel y conserva guedejas de mechones de cabellos alborotados, quizás pertenecientes a un sátiro, un gorgoneion, Júpiter-Ammón o cualquiera otra de las divinidades relacionadas con las aguas, motivo por lo demás recurrente en los complejos termales (Noguera 1993: 267). Por otro lado, quizás a la decoración escultórica de las Termas del Foro pudo pertenecer la estatua de un joven muchacho ataviado con clámide, recuperada en 1946 en la calle de la Caridad, esquina Arco de la Caridad, muy cerca del complejo termal (Trillmich 1979: 347-359 y Noguera 1993: 267-268). 


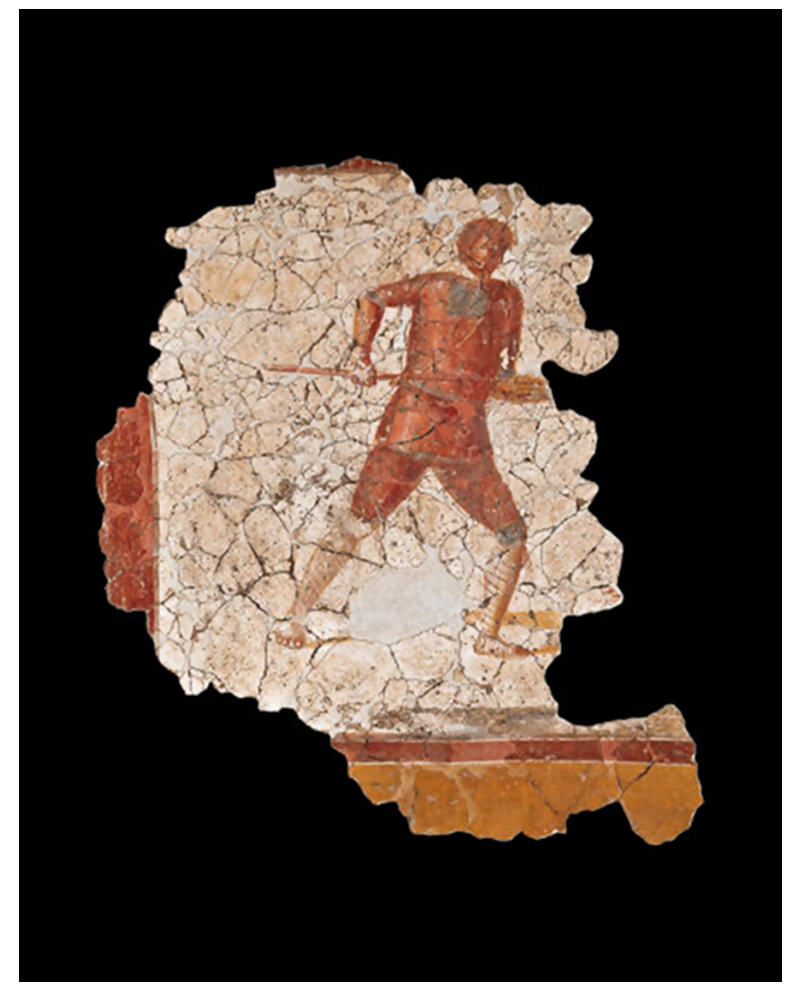

Figura 9. Fragmento del panel con representación del venator, perteneciente a la fase II del pórtico (fotografía J. F. González).

Respecto a la decoración pictórica, solo es conocida, muy parcialmente, en los complejos de naturaleza pública. Destaca una escena de venatio (fig. 9), ubicada en el pórtico de entrada a las Termas del Puerto tras la reforma experimentada por este espacio a finales del siglo I o inicios del II d.C. (fase II del pórtico), en la cual se evoca una escena caza de la que solo resta, bajo un friso de cubos pintados en perspectiva, parte de un panel con un venator combatiendo con un animal salvaje, probablemente un jabalí (conservado muy parcialmente). Estilo e iconografía sugieren datar la composición entre los años 110-140, posiblemente bajo el reinado de Adriano (Noguera et al. 2011: 186-188). La decoración recuperada en las Termas del Foro responde, en cambio, a motivos como candelabros sobre fondo blanco de los interpaneles y un esquema decorativo a base de círculos secantes (Suárez 2011: 119 y 122), fechados también en época de Adriano.

De la decoración pavimental documentada, destacan dos ejemplos: por un lado, el opus sectile de la fase II del frigidarium de las Termas del Puerto, construido a base de grandes lastras marmóreas donde se ha identificado mayoritariamente breccia corallina o marmor sagaricum, pero también algunas lastras de breccia pavonazza, breccia dorata y portasanta (Madrid et al. 2015: 20); y por otro, el pavimento de opus signinum del balneum de la calle Palas dotado de decoración elaborada con teselas blancas y negras (Antolinos 2006b: 93), en la cual se han identificado dos líneas paralelas conformando un marco y, al interior, una orla de eses invertidas rematadas en espiral (fig. 6).

Por otro lado, en lo concerniente a la tecnología usada para la construcción de estos complejos, debemos resaltar en primer lugar los elementos relacionados con los sistemas de hypocausis: hypocaustum, suspensura y concameratio. La cámara de calor (hipocausto) está compuesta, en todos los complejos estudiados, por un area de mortero hidráulico o simplemente de tierra apisonada y una sucesión de pilae (hemos excluimos del análisis las refacciones y reparaciones de las cámaras por estar realizadas con materiales de desecho, a menudo cortados y ensamblados toscamente), en la mayoría de los casos del tipo "pilette clasique A" de Degbomont, correspondiente a un pilar de sección cuadrangular donde no hay diferenciación entre el cuerpo, la base y el coronamiento. El único complejo que se aleja de este tipo de pilae es el de las Termas del Foro, donde las pilae presentaban sección circular, atribuibles al tipo "pilette clasique D”, sin diferenciación, también en este caso, entre el cuerpo y los extremos del pilar (Degbomont 1984: 99-101, especialmente fig. 159). Por otro lado, también es notoria la ausencia de hipocausto en la estancia identificada como sudatio en el balneum de la calle Palas, calefactada gracias al calor absorbido del tepidarium y praefurnium adyacentes, así como mediante braseros portátiles, posiblemente metálicos, a cuyo uso corresponden probablemente las quemaduras en el pavimento de signinum (fig. 8).

Respecto a la suspensura, todos los complejos comparten el mismo esquema en tres niveles: el primero, apoyado directamente sobre las pilae y compuesto por ladrillos bessales o bipedales; el segundo, consistente en una lechada más o menos gruesa de preparado sobre el que se asentará el pavimento superior de la estancia, diferente en cada caso, que corresponde al tercer nivel.

Por último, las concamerationes de las salas de baño se han podido individualizar en las Termas del Puerto y en el balneum de la calle Palas (fig. 10), en particular gracias a diverso material cerámico documentado en excavación. Destaca en ambos casos el empleo de clavi coctiles de los tipos 1a y 4a de Sanz Gamo (1987: 225-226 y fig. 2.1 y 5.1 y 2, Torrecilla 1999: fig. 1.1-3 y 2.1-4). Estas piezas cerámicas, ampliamente constatadas en el Sureste y Levante peninsular, contribuían a la distribución del aire y a la sujeción de la doble pared de 


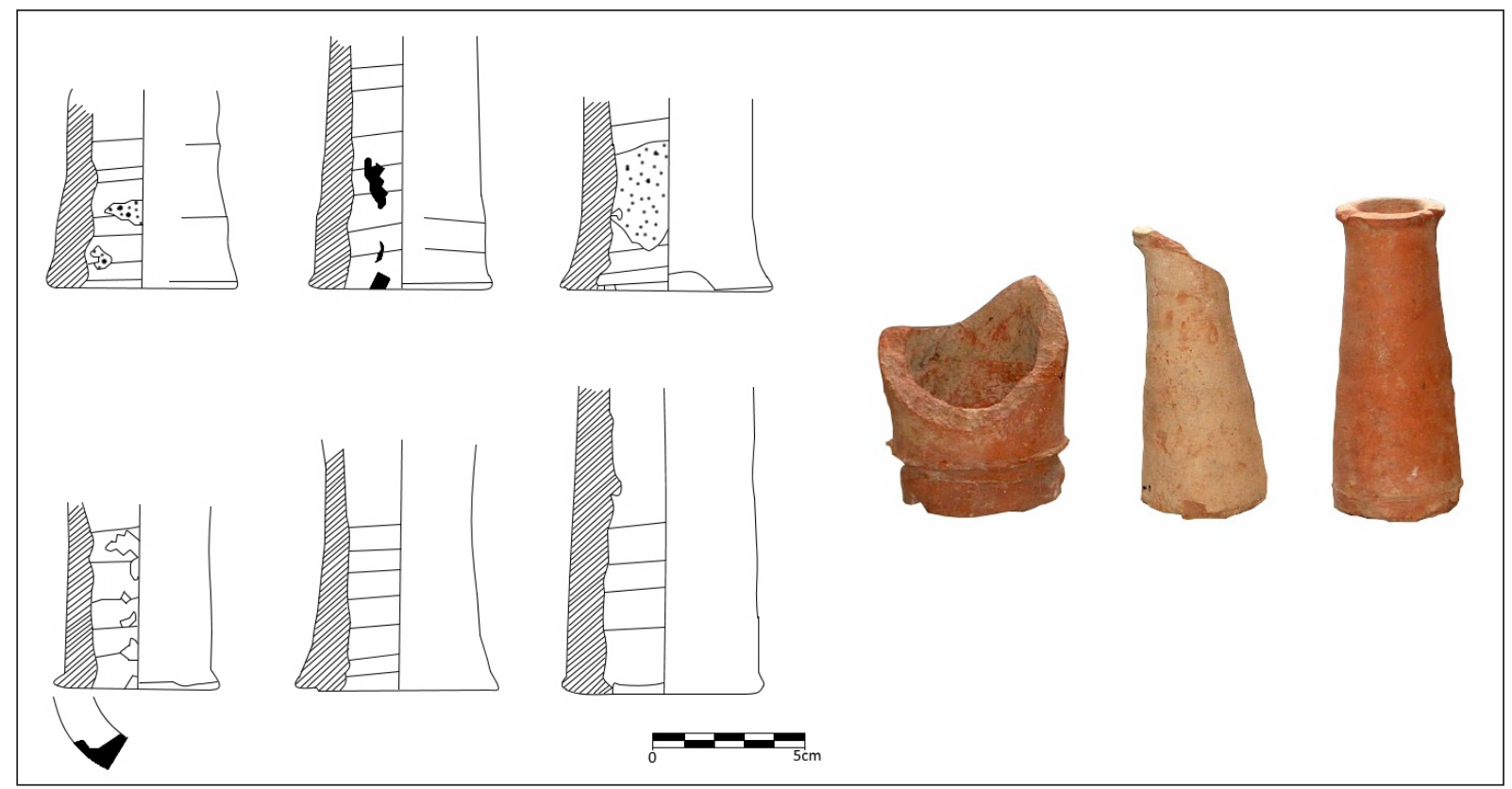

Figura 10. Clavi coctiles tipo 4a. De las Termas del Puerto (a la izquierda) (Madrid, Murcia, 2003) y de la calle Palas (a la derecha) (fotografía J.A. Antolinos).

las estancias calefactadas. El tipo 1a ha sido documentado en complejos como el de Balazote (Santos 1977: 369), Chinchilla (Sanz Gamo 1987: 226) o Ilici (Ramos 1975: 191), entre otros. Mientras que el tipo 4a, también descrito como "tubos espaciadores", se ha documentado mayoritariamente en la zona catalana, aunque con ramificaciones hacia la Meseta, el Valle del Ebro y el Sureste, con ejemplos en la Villa del Empalme, Caravaca (Ramallo 1989-90: 5-6) o en la villa del Cementerio de los Moros de Cabañas del Ebro (Lostal 1977: 192), entre otros (Torrecilla 1999: 402-403).

\section{CONCLUSIONES}

La paulatina aparición de complejos termales públicos y balnea domésticos en las ciudades hispanas constituye un fiel reflejo de la adopción y expansión de las costumbres romanas $y$, en concreto, del hábito del baño como parte de la rutina diaria de sus gentes. Los nuevos usos deben ser entendidos como práctica higiénica y como medio de socialización y de creación de lazos de índole clientelar en el contexto de la comunidad. La introducción del hábito del baño en Hispania también debe ser puesta en relación con el lento, aunque inexorable, proceso de romanización de las comunidades hispanas prerromanas; en este proceso, como en tantos otros, destacó el papel de las gentes de procedencia itálica y los comerciantes de origen griego asentados en el territorio peninsular, especialmente en las ciudades costeras del Levante, desde donde la costumbre del baño, de la cual ellos participaron de forma activa, se fue extendiendo y afianzando entre el resto de la población. Al margen de su valor como indicador de este proceso, las instalaciones termales fueron asimismo espacios emblemáticos donde se exhibía la pertenencia a una cultura común, en el caso de las termas públicas, o a un grupo social determinado -la élite-, en el caso de los balnea domésticos (García-Entero 2005: 867), que afirmó su poder mediante la riqueza arquitectónica y ornamental desplegada en los edificios públicos de su propia ciudad y en sus propias casas.

En el caso de Carthago Nova, la consolidación de esta nueva costumbre se sustanció de forma paulatina desde época tardorrepublicana, constatándose su periodo de mayor esplendor durante el siglo I y la primera mitad del II d.C., momento en que estuvieron en funcionamiento la mayoría de los complejos termales -públicos y privados- y sus infraestructuras asociadas; en el caso de los de naturaleza pública, perdurando hasta el siglo IV d.C., periodo en que los edificios fueron definitivamente abandonados, reocupados en parte y sistemáticamente expoliados en busca de material constructivo reutilizable para la construcción de la ciudad tardorromana. 
Independientemente de su naturaleza pública o privada, los conjuntos termales de Carthago Nova participaron de las corrientes arquitectónicas, los modelos tipológicos y los esquemas básicos -funcionales, constructivos, decorativos...- difundidos desde la península italiana al conjunto del Imperio. Los modelos empleados y su adopción por la población debieron adecuarse a los caracteres específicos del entorno, siendo de especial importancia en nuestro caso la peculiar orografía urbana, las dificultades para su abastecimiento hídrico y su condición de enclave estratégico y gran puerto en los circuitos comerciales del Mediterráneo occidental.

\section{Agradecimientos}

Este trabajo se ha realizado en el marco del proyecto de investigación Exemplum et spolia. El legado monumental de las capitales provinciales romanas de Hispania. Perduración, reutilización y transformación en Carthago Nova, Valentia y Lucentum (HAR2015-64386-C4-2-P), subvencionado por el Ministerio de Economía y Competitividad del Gobierno de España.

La inclusión del edificio de baños Insula II en el presente trabajo ha sido posible gracias a la generosidad y ayuda del equipo del Parque Arqueológico del Molinete, entidad a que agradezco su colaboración.

\section{BIBLIOGRAFÍA}

Abascal Palazón, J. M. (2002): "La fecha de la promoción colonial de Carthago Noua y sus repercusiones edilicias". Mastia 1 (segunda época): 21-44.

Abascal Palazón, J. M. (2009): "Fragmento de placa epigráfica”, en J.M. Noguera Celdrán y M. J. Madrid Balanza (eds.), Arx Hasdrubalis. La ciudad reencontrada. Arqueología en el Cerro del Molinete, Cartagena: 256. Murcia, Tres Fronteras.

Abascal Palazón, J.M.; Almagro-Gorbea, M. y Cebrián, R. (2004): Segobriga, Guía del Parque Arqueológico. Madrid, Real Academia de la Historia.

Andreu Pintado, J. (2000): "Evergetismo edilicio sobre termas en Hispania", en Termas romanas en el Occidente del Imperio: II Coloquio internacional de arqueología en Gijón: 289-294. Gijón (1999), Gijón, VTP Editorial.

Andreu Pintado, J. (2004): Edictum, Municipium y Lex: Hispania en época Flavia (69-96 d. C.). BAR International Series 1293. Oxford, Archeopress.
Andreu Pintado, J. (2004b): “Construcción pública y municipalización en la provincia Hispania Citerior: la época Flavia". Iberia 7: 39-75.

Antolinos Marín, J.A. (2006a): "Hallazgos íberos, púnicos y romanos en Cartagena; excavación en la calle Palas 5-7", en XVII Jornadas de Patrimonio Histórico: 101-104. Cartagena (2006), Murcia, Servicio de Patrimonio Histórico.

Antolinos Marín, J. A. (2006b): Memoria de la intervención arqueológica de urgencia en calle Palas 5-7 de Cartagena: 89-100. Murcia, Archivo del Servicio de Patrimonio Histórico de Murcia.

Arasa i Gil, F. (2004): "La decoración escultórica de las uillae del País Valenciano", en Actas de la IV Reunión sobre escultura romana en Hispania: 229253. Lisboa (2002), Madrid, Ministerio de Educación y Ciencia.

Bernal Casasola, D.; Expósito Álvarez, J.A.; Díaz Rodríguez, J.J. y Muñoz Vicente, A. (2016): Las Termas Marítimas y el Doríforo de Baelo Claudia. Cádiz, Servicio de Publicaciones de la Universidad de Cádiz.

Brundrett, N.G.R. y Simpson, C.J. (1997): "Innovation and the Baths of Agrippa". Athenaeum 85: 220-227.

Candilio, D. (1991): "La decorazione scultorea delle terme imperiali”, en M.R. Di Mino (coord.), Rotunda Diocletiani. Sculture decorative delle terme nel Museo Nazionale Romano: 15-24. Roma, Leonardo Arte.

Cascales, F. (1597): Discurso de la ciudad de Cartagena. Valencia. E. Ortiz Ballester (ed. Lit). Valencia (1999), Lemir: Revista de Literatura Española Medieval y del Renacimiento.

Curchin, L.A. (1983): "Wealth in Roman Spain". Historia: Zeitschrift für Alte Geschichte 32: 227-244.

Degbomont, J.M. (1984): Hypocaustes. Le chaufage par hypocause dans l'habitat privé. Lieja, Eraul 17.

Delaine, J. (1989): "Some observations on the transition from Greek to Roman Baths in Hellenistic Italy". Mediterranean Archaeology 2: 111-125.

Domergue, C. (1990): Les mines de la Péninsule Ibèrique dans 1' Antiquité Romaine. Collection de l'École française de Rome, 127. Roma. http://www. persee.fr/doc/efr_0000-0000_1990_ths_127_1 [10/09/2016].

Egea Vivancos, A. (2001- 2002): “Abastecimiento y distribución urbana del agua en Qart- Hadast: la continuidad en época republicana". Estudios Orientales 5-6: 527-538.

Egea Vivancos, A. (2004): “Ingeniería hidráulica en Carthago Nova; las cloacas y la red de saneamiento". Mastia 3: 71-94. 
Egea Vivancos, A. (2011): "Los Balnea privados de Carthago Nova", en J.M. Noguera y M.J. Madrid (eds.), Arx Hasdrubalis. La ciudad reencontrada. Arqueología en el Cerro del Molinete, Cartagena: 84-89. Murcia, Tres Fronteras.

Egea Vivancos, A.; Ruiz Valderas, E. y Vizcaino Sánchez, J. (2011): "Carthago Nova”, en J.A. Remolà Vallverdú y J. Acero Pérez (coords.) La gestión de los residuos urbanos en Hispania: 281-296. Anejos del Archivo Español de Arqueología, LX. Madrid, CSIC.

Eschebach, H. (1979): Die Stabianer Thermen in Pompeji. Berlín, De Gruyter.

Fagan, G.G. (2001): "The genesis of the Roman public bath: recent approaches and future directions". American Journal of Archaeology 105: 403-426.

Fernández Carvajal, B. (2006): "Excavación de urgencia en la calle Puertas de Murcia, esquina Subida a San Antonio (Cartagena)", en XVII Jornadas de Patrimonio Histórico: 111- 112. Cartagena (2006), Murcia, Gobierno de la Región de Murcia.

Fernández Ochoa, C. y García-Entero, V. (1999): "Las termas romanas del noroeste y la Meseta norte de Hispania. Los modelos arquitectónicos". Archivo Español de Arqueología 72: 141-166.

Fernández Ochoa, C.; Morillo Cerdán, A. y Zarzalejos Prieto, M. (2000): "Grandes conjuntos termales públicos de Hispania", en Termas Romanas en el Occidente del Imperio: II Coloquio Internacional de Arqueología en Gijón: 59-72, Gijón (1999), Gijón, VTP Editorial.

Fernández Villamarzo, M. (1907): Estudios GráficoHistóricos de Cartagena. Desde los tiempos prehistóricos hasta la expulsión de los árabes. Cartagena, Artes Gráficas de Levante.

García-Entero, V. (2005): Los Balnea domésticos -ámbito rural y urbano- en la Hispania Romana. Anejos del Archivo Español de Arqueología XXXVII. Madrid, CSIC.

García Fernández, E. (2001): El municipio latino. Origen y desarrollo constitucional. Anejos de Gerión V. Madrid, Universidad Complutense.

García Martín Morales, A. (2007): "La decoración musiva de los edificios termales de la Bética", en Miscelánea en homenaje a Victoria Cabrera, II: 158-169. Alcalá de Henares, Museo Arqueológico Regional de Alcalá de Henares.

Gómez Araujo, L. (2013): “Revisión interpretativa y cronológica de las termas de Baelo Claudia: nuevas propuestas". Antiquitas 25: 165-176.

González Simancas, M. (1905-1907): Catálogo monumental de España. Provincia de Murcia. Murcia,
Facsímil del Colegio de Arquitectos de Murcia (1997).

Guidobaldi, F. y Conte, G. (2011-2012): “La parte centrale delle Terme di Agrippa nel Campo Marzio: una totale o parziale ricostruzione a fundamentis in Età Tardocostantiniana". Rivista di Archeologia Cristiana 87-88: 175-208.

Guini, G. (1999): "Thermae Agrippae", en E.M. Steinby (coord.), Lexicon Topographicum Urbis Romae V: 40-42. Roma, Edizione Quasar.

Guiral Pelegrín, C. (2000): “Decoración pictórica de los edificios termales", en Termas Romanas en el Occidente del Imperio: II Coloquio Internacional de Arqueología en Gijón: 115-121. Gijón (1999), Gijón, VTP Editorial.

Hartmann, E. et al. (1995): "Skulpturenausstattung in Thermen", en K. Stemmer (ed.), Standorte. Kontext und Funktion antiker Skulptur. Ausstellungskatalog Abgußsammlung antiker Plastik: 388-398. Berlín, Freunde \& Förderer.

Kremer, D. (2006). Ius Latinum. Le concept de Droit Latin sous la République et l'Empire. París, De Boccard.

Krencker, D. (1938): Der Schlussel zum Verstandnis der grossen Thermen Roms: Ein technisch-wirtschaftliches Problem. Berlin.

Koppel, E.M. (1995): "La decoración escultórica de las villae romanas de Hispania”, en J.M. Noguera Celdrán, (coord.), Poblamiento rural romano en el sureste de Hispania: 27-48. Jumilla (1993), Murcia, Universidad de Murcia.

Koppel, E.M. (2004): "La decoración escultórica de las termas en Hispania", en Actas de la IV Reunión sobre escultura romana en Hispania: 339-366. Lisboa (2002), Madrid, Ministerio de Educación y Ciencia.

Labarthe, J.M.; Navarro Caballero, M.; Magallón Botaya, M.A.; Sáenz, C.; Rico, C.; Fincker, M. y Sillièrs, P. (2000): "Las termas de la ciudad hispanoromana de Labitolosa: avance a su estudio", en Termas romanas en el Occidente Del Imperio: II Coloquio internacional de arqueología en Gijón: 193-198, Gijón (1999), Gijón, VTP Editorial.

Le Roux, P. (1986): "Municipe et droit latin en Hispania sous l'Empire". Revue Historique de Droit 64(3): 325-330.

López Martínez, M.V. y Egea Vivancos, A. (2008): "Excavación arqueológica en calle Serreta esquina calle Martín Delgado, Cartagena”, en XIX Jornadas de Patrimonio Cultural de la Región de Murcia: 275-278. Cartagena, Alhama de Murcia, La Unión y Murcia (2008), Murcia, Tres Fronteras. 
Lostal, J. (1977): "Una villa romana en Urrea del Jalón (Zaragoza)". Estudios del Seminario de Prehistoria, Arqueología e Historia Antigua de la Universidad de Zaragoza 3: 185-210.

Lumiares, Conde de (1796): Inscripciones de Carthago Nova, hoy Cartagena, en el reino de Murcia, ilustradas por el Excelentísimo Señor Conde de Lumiares, individuo de la Academia de Artes y Ciencias de Padua. Madrid. Facsímil Tabularium de Murcia (2002), Murcia.

Madrid Balanza, M.J. y Murcia Muñoz, A.J. (2003): "Las termas de la calle Honda-Plaza de los Tres Reyes de Cartagena: material latericio y problemas de inserción urbana", en J. M. Noguera (coord.), Arx Asdrubalis: arqueología e historia del cerro del Molinete de Cartagena: 231-268. Murcia, Editum.

Madrid Balanza, M.J.; Pavía Page, M. y Noguera Celdrán, J.M. (2015): "Las Termas del Puerto de Carthago Nova: un complejo augusteo de larga perduración", en Tarraco Biennal, 2on Congrés Internacional d'Arqueologia y Mon Antic. August $i$ les Províncies Occidentals, II: 15-22. Tarragona (2014), Tarragona, Fundación Privada Mutua Catalana.

Manderscheid, H. (1994): “Aspekte der Mosaikausstattung in öffentlichen un privaten Thermenanlagen", en La mosaïque gréco-romaine IV. Actes du IVe Colloque international pour l'étude de la mosaïque Antique: 61-66. Trèves (1984), Paris, Association Internationale pour l'étude de la Mosaïque Antique.

Marín Baño, C. y De Miquel Santed, L.E. (1995): "Obras hidráulicas en Carthago-Nova", en XXI Congreso Nacional de Arqueología: 1165-1182. Teruel, (1991), Zaragoza, Diputación General de Aragón.

Marín Díaz, A. (1988): Emigración, colonización y municipalización en la Hispania Republicana. Granada, Universidad de Granada.

Martín Bueno, M. y Liz Guiral, J. (1999): "Las termas del Municipipum Augusta Bilbilis y su relación con otros edificios análogos", en Roman baths and bathing. Proceedings of the First International Conference on Roman Baths: 251-262. Bath (1992), Portsmouth, Roman of Journal Archaeology.

Martín Camino, M. y Roldán Bernal, B. (1997): “Calle Serreta, números 8-10-12", en Memorias de Arqueología. Excavaciones arqueológicas en Cartagena 1982-1988: 74-94. Murcia, Gobierno de la Región de Murcia.

Martínez Andreu, M. (1997): "Las termas romanas de la calle Honda", en Memorias de Arqueología.
Excavaciones arqueológicas en Cartagena 19821988: 12-14. Murcia, Gobierno de la Región de Murcia.

Melchor Gil, E. (1992): "Evergetismo y distribuciones en la Hispania Romana". Florentia Iliberritana 3: 49-72.

Melchor Gil, E. (1993): “Construcciones cívicas y evergetismo en Hispania”. Espacio, Tiempo y Forma, Serie II, Historia Antigua 6: 443-466.

Munuera Navarro, D. (2003): "Aproximación al estudio de unas murallas casi olvidadas: el informe del ingeniero militar Lorenzo Possi sobre las fortificaciones urbanas de Cartagena (1669)". Revista ArqueoMurcia 1: 3-26.

Nielsen, I. (1985): "Le prime fasi dell'evoluzione dell'edificio termale romano". Analecta Romana Instituti Danici XIV: 81-112.

Nielsen, I. (1999): "Early provincial baths and their relation to early Italic baths", en Roman Bath and Bathing. Proceedings of the First International Conference on Roman Baths: 67-74. Bath (1992), Portsmouth, Roman of Journal Archaeology.

Noguera Celdrán, J.M. (2003): "La escultura romana de Carthago Nova: notas para un estado de la cuestión", en Actas de la I reunión sobre escultura romana en Hispania: 263-276. Mérida (1992), Madrid, Ministerio de Cultura.

Noguera Celdrán, J. M. (2012): “Carthago Nova: Urbs privilegiada del Mediterráneo occidental”, en J. Beltrán y O. Rodríguez (eds.), Hispaniae urbes. Investigaciones arqueológicas en ciudades históricas: 121-190. Sevilla, Editorial Universidad de Sevilla.

Noguera Celdrán, J.M. y Soler Huertas, B. (2011): “Urban development and monumentalization in the Roman colony Urbs Iulia Nova Karthago (Cartagena, Hispania Citerior)", en Roma y las provincias: modelo y difusión. Actas del XI Coloquio Internacional del Arte Romano Provincial, II: 1095-1101. Mérida (2009), Roma, L'Erma.

Noguera Celdrán, J. M.; Fernández Díaz, A. y Madrid Balanza, M. J. (2011): "Nuevas pinturas murales en Carthago Nova: los ciclos de las Termas del Foro y del Edificio del atrio", en J.M. Noguera y M. J. Madrid Balanza (eds.), Arx Hasdrubalis. La ciudad reencontrada. Arqueología en el Cerro del Molinete, Cartagena: 185-207. Murcia, Tres Fronteras.

Noguera Celdrán, J. M.; Madrid Balanza, M. J. y Velasco, V. (2011): "Baño y ocio: la Termas del Foro", en J. M. Noguera Celdrán y M. J. Madrid Balanza (eds.), Arx Hasdrubalis. La ciudad reencontrada. 
Arqueología en el Cerro del Molinete, Cartagena: 90-115. Murcia, Tres Fronteras.

Pavía Page, M. (2015): "Las Termas del Puerto de Carthago Nova: contextos de amortización y abandono", en I Jornadas Doctorales de la Universidad de Murcia: 1-5. Murcia (2015), Murcia. http:// congresos.um.es/jdoctorado/jdoctorado2015/index. [20/08/2016]

Pérez Ballester, J. (1998): "El portus de Carthago Nova. Sociedad y comercio tardo-helenísticos”, en Actas de las III Jornadas de Arqueología subacuática. Puertos antiguos y comercio marítimo: 249261. Valencia (1997), Valencia, Conselleria de Educación, Investigación, Cultura y Deporte.

Pérez Olmedo, E. (1996): Revestimientos de opus sectile en la península Ibérica. Studia Archaeologica 84. Valladolid, Universidad de Valladolid.

Ramallo Asensio, S.F. (1989-90): "Termas romanas de Carthago Nova y alrededores". Anales de Prehistoria y Arqueología 5-6: 161-177.

Ramallo Asensio, S.F. y Murcia Muñoz, A.J. (2010): "Aqua et lacus en Carthago Nova. Aportaciones al estudio del aprovisionamiento hídrico en época romana". Zeitschrift für Papyrologie und Epigraphik 172: 249-258.

Ramallo Asensio, S.F. y Ros Sala, M. M. (2012): “La gestión del agua en una ciudad romana de la Hispania semiárida: Carthago Nova como ejemplo de adaptación al medio", en J.M. Gómez Espín y R.M. Hervás Avilés (eds.), Patrimonio hidráulico y cultural del agua en el Mediterráneo: 77-104. Murcia, Campus Mare Nostrum.

Ramos Fernández, R. (1975): La ciudad romana de Ilici. Alicante, Instituto de Estudios Alicantinos.

Robinson, O. (1984): "Baths: aspect of roman local governament law", Sodalitas. Scritti in onore di Antonio Guarino 3: 1070-1081. Nápoles, Editore Jovene.

Roldán Gómez, L. (1994): “Aspects constructifs des thermes romains de la Baetica", en L'Africa romana. Atti dell'XII Convegno di studio: 789-821. Sassari, Editrice Democratica Sarda.
San Martín Moro, P.A. (1973): "Noticiario arqueológico". Mastia 2: s/p.

San Martín Moro, P.A. (1985a): “Cartagena: conservación de yacimientos arqueológicos en el casco urbano", en Primeras Jornadas de Arqueología en las ciudades actuales: 336-355. Zaragoza (1983), Zaragoza, Ayuntamiento de Zaragoza.

San Martín Moro, P.A. (1985b): "Nuevas aportaciones al plano arqueológico de Cartagena". Boletín del Museo de Zaragoza 4: 131-149.

Santos Gallego, S. (1977): "Excavaciones en la villa romana de Balazote (Albacete)", en Segovia. Symposium de Arqueología Romana: 367-370. Segovia (1977), Barcelona, Universidad de Barcelona.

Sánz Gamo, R. (1987): “Algunos materiales romanos utilizados en la construcción de las concamerationes". Oretum 3: 225-236.

Suárez Escribano, L. (2005): "La muralla de Lorenzo Possi (Cartagena s. XVII)". Anales de Prehistoria y Arqueología 21: 197-206.

Suárez Escribano, L. (2006): "Primeros restos de la muralla de L. Possi en la excavación arqueológica de la calle Caballero, 13-17, Cartagena”, en XVII Jornadas de Patrimonio Histórico: intervenciones en el patrimonio arquitectónico y etnográfico de la Región de Murcia: 203-204. Cartagena (2006), Murcia, Gobierno de la Región de Murcia.

Suárez Escribano, L. (2011): "Hallazgo de un nuevo edificio público en Carthago Nova: las termas del Foro". Verdolay 13: 113-125.

Torrecilla Aznar, I. (1999): "Materiales de construcción en las termas de la Hispania Romana, a propósito de los materiales hallados en la villa de El Saucedo (Talavera la Nueva, Toledo)", en Actas del XXIV Congreso Nacional de Arqueología, IV, Romanización y desarrollo urbano en la Hispania republicana: 397-416. Cartagena (1997), Murcia, Gobierno de la Región de Murcia.

Trillmich, W. (1979): "Eine Jünglinsstatue in Cartagena und Überlegungen zur Kopienkritik". Madrider Mitteilungen 20: 339-360. 